\title{
Should PDE5Is be prescribed routinely for all men with newly diagnosed type 2 diabetes?
}

\author{
GEOFFREY HACKETT
}

\begin{abstract}
Diabetes and erectile dysfunction are closely associated. It is good that there is now more awareness of the issue, especially given the strong link to heightened cardiovascular risk. This article challenges current practice and explores the routine use of phosphodiesterase inhibitors.

Br J Diabetes Vasc Dis 2015;15:184-186
\end{abstract}

Key words: type 2 diabetes, erectile dysfunction, cardiovascular risk, phosphodiesterase type 5 inhibitors, lower urinary tract symptoms

\section{Introduction}

I present to my GP as a 53-year-old man with type 2 diabetes (T2DM), HbA1c 6.6 (IFCC 48\%), slightly overweight (body mass index 28.5), BP 125/80, total cholesterol 5.1. I am otherwise fit with an excellent marriage. My sex life is OK but not what it used to be and I am peeing a lot more and stream not what it was. My GP commences me on ramipril and atorvastatin but I am not asked about my erections, despite NICE advice, ${ }^{1}$ so I ask my GP what the diagnosis of T2DM means for my erectile function. He seems very surprised to be asked and offers reassurance.

The reality is that I have a $70 \%$ chance of developing erectile dysfunction (ED) ${ }^{2}$ with a $55 \%$ chance (at best) of responding to oral therapy ${ }^{3}$ by the time I am offered treatment. I point out that my father had diabetes and suffered leg ulcers and also had an enlarged prostate and required two transurethral resections of the prostate (TURPs) in his 60s. He also had poor renal function in later life. I have read that, as a newly diagnosed man with T2DM, I have a $30 \%$ chance of neuropathy ${ }^{4}$ and $32 \%$ increased risk of lower urinary tract symptoms/benign prostatic hyperplasia (LUTS/BPH). ${ }^{5}$

I tell my GP that I have been doing some reading on the subject and, in addition to the ACE inhibitor (ACEI) and statin, which I anticipate will have no immediate benefit on my health, I ask if I could be prescribed an angiotensin receptor blocker (ARB) instead of an ACEI because of the high level evidence that ARBs improve erectile function, ${ }^{6}$ which is an important issue for me - he declines. I ask if I could have my testosterone level measured as I have read that $40 \%$ of men with T2DM have low testosterone, ${ }^{7}$

Good Hope Hospital, Sutton Coldfield, West Midlands, UK

Address for correspondence: Professor G Hackett Consultant in Urology and Sexual Medicine, Good Hope Hospital, Rectory Road, Sutton Coldfield, West Midlands, B75 7RR, UK

Tel: +44 (0)1214242000

E-mail: Geoff.hackett@virgin.net

http://dx.doi.org/10.15277/bjdvd.2015.054
Figure 1. Multifactorial mechanisms associated with ED in diabetes

- Autonomic neuropathy

- Peripheral neuropathy

- Hypertension

- Peripheral vascular disease

- Hyperlipidaemia

- Drug related side effects

- Cavernosal smooth muscle disorder

- Hypogonadism with reduced sexual desire (double risk)

- Psychological factors including depression

- Ejaculatory disorders

- Retrograde/anejaculation

- Reduced sensation

and he declines saying that this was not recommended in guidelines. I ask if I could be prescribed a phosphodiesterase type 5 inhibitor (PDE5I) but he declines again.

\section{The argument for routine use of PDE5Is}

Sexual activity has been shown to reduce the risk of cardiovascular events and mortality, ${ }^{8}$ and regular erections and sexual activity have been shown to protect against ED. ${ }^{9}$ ED has been shown to be independently associated with both depression ${ }^{10}$ and reduced quality of life in diabetes. ${ }^{11}$ The ED prevalence in the primary care population is $70 \%,{ }^{2}$ meaning effectively that those without ED have just not got it yet. The average UK man suffers 3 years before treatment. ${ }^{3}$ In clinical trials with unlimited medication under specialist control, response rates to ED therapy are at best $55-60 \%,{ }^{3}$ due to the multiple pathologies involved in T2DM (Figure 1). Response rates are worse if access to medication is restricted through illogical legislation. ${ }^{3}$ NICE guidance stresses the importance of addressing these co-morbidities as well as prescribing the PDE5I with lowest acquisition costs. ${ }^{1}$

\section{Economic issues}

Generic sildenafil costs approximately 20p at NHS tariff, meaning that twice weekly dosing would be $f 1.60$ per month or $f 5.60$ with daily dosing. Every patient in the $45 \%$ who subsequently fail with the PDE5I will cost $f 12-15$ for each dose of second line therapy, such as alprostadil or MUSE, meaning $£ 48-60$ per month for sexual activity once per week or $£ 96-f 120$ per month for activity twice per week. ${ }^{12}$ Each case will usually require secondary care referral at $\mathrm{f} 120$ with an average of three follow-up visits at $f 80$ to teach the injection process. There is also a strong economic argument for 
measuring and correcting low testosterone levels to augment response to oral therapy as this will result in considerable savings compared with expensive second line medications. ${ }^{13}$ This is a particular issue in patients with chronic stable angina, where nitrate use prevents the use of PDE5Is, with secondary care referral being required for expensive second line therapies. As nitrates have no prognostic benefit in angina, ${ }^{3}$ changing to a newer anginal therapy to facilitate generic PDE5I use may be beneficial to the patient as well as being extremely cost effective.

\section{Depression}

The prevalence of depression in men with diabetes is around $25 \%^{10}$ and PDE5Is have been shown to improve depression scores both with and without antidepressants. ${ }^{14}$

\section{LUTS/BPH}

Recent evidence has shown that LUTS/BPH is strongly linked to obesity, insulin resistance, pelvic atherosclerosis, inflammation and increased sympathetic activity. ${ }^{15}$ PDE5 inhibition improves many of these parameters and PDE5Is are now licensed to treat LUTS/BPH. ${ }^{16}$ As the effect is primarily through improved endothelial function, this is likely to reduce disease progression through modification of risk factors, whereas standard therapy with alpha-blockade has been repeatedly shown not to influence LUTS/BPH progression and to be associated with ejaculatory problems in around $30 \%$ of patients. ${ }^{16}$

\section{Cardio-prevention}

Three studies have shown reduced all cause and cardiovascular mortality in men with coronary artery disease and T2DM. ${ }^{17-19}$ Several studies have shown benefits in angina and hypertension, as these were the original targets for PDE5Is. ${ }^{20}$ Beneficial mechanisms include improved endothelial function, enhanced cGMP and CAMP activity to counterbalance hypertrophic and pro-apoptotic signalling and enhanced post-ischaemic reperfusion. ${ }^{20}$ PDE5Is are clearly important cardiovascular drugs as they are first line treatment for primary pulmonary hypertension. ${ }^{21}$

\section{Diabetic peripheral neuropathy (DPN)}

There are numerous case reports of improvement in neuropathic pain and paraesthesia with PDE5Is.22,23 Nitric oxide is the major neurotransmitter of the vasa nervorum, suggesting an important preventive role in microvascular complications. ${ }^{4}$ Currently, drugs used to treat established DPN effectively block pain pathways and frequently aggravate ED. ${ }^{12}$ There is huge potential for savings by the prevention of complications of DPN.

\section{Diabetic nephropathy}

The multiple potential benefits of PDEls in renal disease are summarised in Figure 2 taken from Afsar et al. ${ }^{24} \mathrm{~A}$ recent double blind placebo control of sildenafil in obese men and women with type 2 diabetes showed a reduction in albumen creatinine

Figure 2. Mechanisms of nephroprotective effect of phosphodiesterase 5 inhibitors

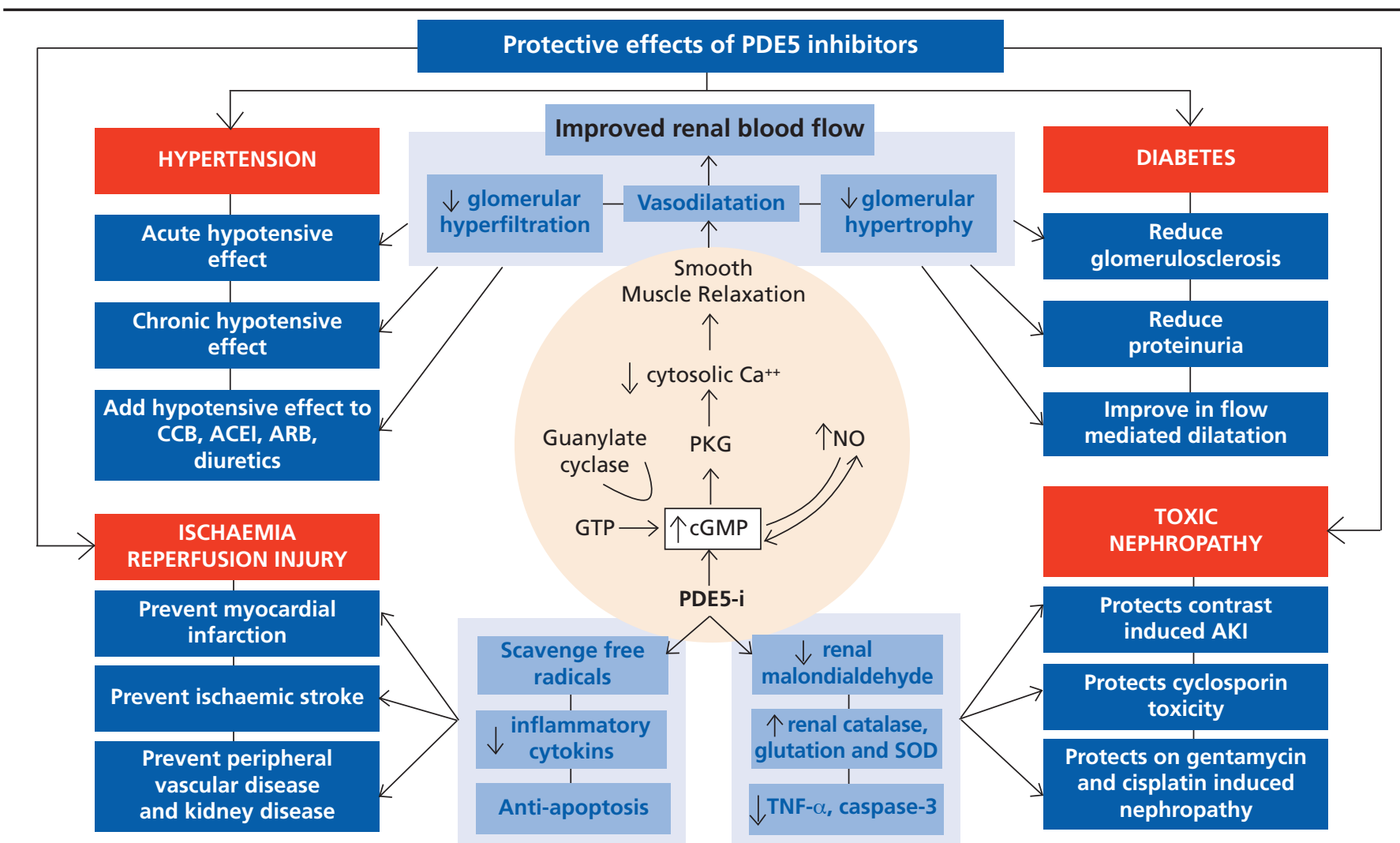

NO=Nitric Oxide; GTP=Guanosine Triphosphate; $c$ GMP=Cyscline Guanosine Monophospate; $C C B=C$ alcium Channel Blocker; $A$ RB=Angiotensin Receptor Blocker; $\mathrm{ACEl}=$ Angiotensin Converting Enzyme Inhibitor; $\mathrm{AKI}=$ Acute Kidney Injury; TNF=Tumour Necrosis Factor; PKG=cGMP-dependent protein kinase 


\section{Key messages}

- The prevalence of erectile dysfunction (ED) in type 2 diabetes can be as high as $75 \%$

- The average UK patient suffers for over 3 years before seeking help and by then response rates are little better than $50 \%$

- By asking about ED and treating early with inexpensive PDE5Is, considerable savings will be made on expensive poorly tolerated second line medications

- There is emerging evidence that PDE5Is may have considerable cardiovascular benefits in T2DM

excretion ratio increased insulin sensitivity and reduced markers of endothelial dysfunction. ${ }^{25}$

\section{Summary}

I could of course wait 10 years for a series of randomised clinical trials to establish these potential benefits, but it is likely that this news will arrive too late for me. In reality they are unlikely to be conducted as these drugs are now generic and there is no financial motivation to conduct what would be very expensive trials. I know that PDE5Is are now cheap, with a remarkable safety record over 16 years and benefits that will be evident almost immediately.

I have weighed up the evidence and have decided to take daily PDE5Is from the time of diagnosis, funding the $£ 5.60$ myself. I will give up my pint of lager and pork scratchings on Saturday night once a month to fund this. The effect of the PDE5Is might even make next Saturday night more enjoyable!

I have decided to have this conversation with all my male patients with T2DM so that they might be protected until the rest of the diabetes world comes to the logical conclusion of commencing the PDE5I at the same time as the statin and ACEI/ARB. I note that my GP practice leaflet states that they offer a personalised service in diabetes.

\section{Conflict of interest Occasional speaker for Lilly and Bayer. Funding None.}

\section{References}

1. Home P, Mant J, Diaz J, Turner C, on behalf of the Guideline Development Group. Management of type 2 diabetes: Summary of updated NICE guidance. BMJ 2008;336:1306-08. http://dx.doi.org/10.1136/bmj.39560.442095.AD

2. Hackett G, Cole N, Deshpande A, Popple M, Kennedy D, Wilkinson P. Biochemical hypodonadism and type 2 diabetes in primary care. $\mathrm{Br} J$ Diabetes Vasc Dis 2009;9:226-31. http://dx.doi.org/10.1177/1474651409342635

3. Hackett G, Kell P, Ralph D, et al. British Society for Sexual Medicine guidelines on the management of erectile dysfunction. J Sex Med 2008; 5:1841-6. http://dx.doi.org/10.1111/j.1743-6109.2008.00773.x

4. Krentz A, Mani R, Shearman C. Peripheral arterial disease in diabetes: time for co-ordinated approach to management. Br J Diabetes Vasc Dis 2003;3:92-6. http://dx.doi.org/10.1177/14746514030030020301

5. Rosen R, Altwein J, Boyle P, et al. Lower urinary tract symptoms and male sexual dysfunction: the multinational survey of the aging male (MSAM-7). Eur Uro/ 2003;44:637-49. http://dx.doi.org/10.1016/j.eururo. 2003.08.015
6. Doumas M, Douma S. The effect of antihypertensive drugs on erectile function: a proposed management algorithm. J Clin Hypertens 2006; 8:359-63. http://dx.doi.org/10.1111/j.1524-6175.2005.05285.x

7. Dhindsa S, Miller MG, McWhirter CL, et al. Testosterone concentrations in diabetic and nondiabetic obese men. Diabetes Care 2010;33:118692. http://dx.doi.org/10.2337/dc09-1649

8. Hall SA, Shackleton R, Rosen RC, Araujo AB. Sexual activity, erectile dysfunction and incident cardiovascular events. Am J Cardiol 2010;105: 192-7. http://dx.doi.org/10.1016/. amjcard.2009.08.671

9. Koskimaki J, Shiri J, Tammela T. Regular sexual activity protects against erectile dysfunction. The Tampere Male ageing study. Am J Med 2008;21:592-6. http://dx.doi.org/10.1016/j.amjmed. 2008.02.042

10. de Groot M, Anderson R, Freedland K, Clourse RE, Lustman PJ. Association of depression and diabetes complications: a meta-analysis. Psychosom Med 2001;63:619-30. http://dx.doi.org/10.1097/00006842-200107000-00015

11. Brooke JC, Walter DJ, Kapoor D, Marsh H, Muraleedharan V, Jones TH. Testosterone deficiency and severity of erectile dysfunction are independently associated with reduced quality of life in men with type 2 diabetes. Andrology 2014;2:205-11. http://dx.doi.org/10.1111/j.2047-2927. 2013.00177.x

12. NHS availability of erectile dysfunction drugs: proposed changes. https://www.gov.uk/government/consultations/nhs-availability-of-erectile-dysfunction-drugs-proposed-changes

13. Buvat J Montorsi F, Maggi M, et al. Hypogonadal men nonresponders to the PDE5 inhibitor tadalafil benefit from normalization of testosterone levels with a $1 \%$ hydroalcoholic testosterone gel in the treatment of erectile dysfunction (TADTEST study). J Sex Med 2011;8:284-93. http://dx.doi.org/10.1111/j.1743-6109.2010.01956.x

14. Seidman SN, Roose SP, Menza MA, et al. Treatment of erectile dysfunction in men with depressive symptoms: results of a placebo-controlled trial with sildenafil citrate. Am J Psychiatry 2001;158:1623-30. http://dx.doi.org/10.1176/appi.ajp.158.10.1623

15. Kirby M, Chapple C, Jackson G, et al. Erectile dysfunction and lower urinary tract symptoms: a consensus on the importance of co-diagnosis. Int J Clin Pract 2013;67:606-18. http://dx.doi.org/10.1111/ijcp.12176

16. Chapple CR, Roehrborn CG, McVary K. Effect of tadalafil on male lower urinary tract symptoms: an integrated analysis of storage and voiding international prostate symptom subscores from four randomised controlled trials. Eur Urol 2015;67:114-22. http://dx.doi.org/10.1016/j.eururo.2014.08.072

17. Gazzaruso C, Solerte SB, Pujia A, et al. Erectile dysfunction as a predictor of cardiovascular events and death in diabetic patients with angiographically proven asymptomatic coronary artery disease: a potential protective role for statins and 5-phosphodiesterase inhibitors. J Am Coll Cardiol 2008;51:2040-4. http://dx.doi.org/10.1016/j.jacc.2007.10.069

18. Anderson SG, Hutchings DC, Kwok CS, Trafford AW, Heald AH. Phosphodiesterase type $\mathrm{V}$ inhibitors use in type 2 diabetes is associated with reduced all-cause mortality. Poster LB-9, ADA 2015.

19. Hackett GI, Heald AH, Ramachandran S. Testosterone replacement therapy and PDE5 inhibitor use are independently associated with a reduction in allcause mortality in men with type 2 diabetes. Poster LB-7, ADA 2015.

20. Giannetta E, Feola T, Gianfrilli D, et al. Is chronic inhibition of phosphodiesterase type 5 cardioprotective and safe? A meta-analysis of randomized controlled trials. BMC Med 2014:12:185. http://dx.doi.org/10.1186/s12916-014-0185-321.

21. Guazzi M, Borglaug B. Pulmonary hypertension due to left heart disease. Circulation 2012;126:975-90. http://dx.doi.org/10.1161/CIRCULATIONAHA.111.085761

22 Hackett G. PDE5 inhibitors in diabetic peripheral neuropathy. Int J Clin Pract 2006;60:1123-6. http://dx.doi.org/10.1111/j.1742-1241.2006. 01087.x

23. Sairam K, McNicholas T. Sildenafil in diabetic peripheral neuropathy. Br J Diabetes Vasc Dis 2002;2:304. http://dx.doi.org/10.1177/14746514020020042401

24. Afsar B, Ortiz A, Covic A, Phosphodiesterase type 5 inhibitors and kidney disease. Int Urol Nephrol 2015:47:1521-8. http://dx.doi.org/10.1007/s11255-015-1071-4

25. Ramirez CE, Nian $\mathrm{H}, \mathrm{Yu}$ C, et al. Treatment with sildenafil improves insulin sensitivity in prediabetes: a randomized, controlled trial. J Clin Endocrinol Metab 2015:100:4533-40. http://dx.doi.org/10.1210/jc.2015-3415 